\title{
Finite element analysis of shear bearing capacity of "T" joints of acromegaly steel slab shaped steel concrete special-shaped columns
}

\author{
Xingxian Zhang
}

(Yunnan Open University,KunMing,China ,650223, 630673509@qq.com)

Keywords: type steel coagulant special-shaped columns; "T" shaped joints; shear bearing capacity Abstract. The purpose of this study is to analyze the shear capacity of a steel slab shaped steel concrete column joint (SRC node for short).Compared with real abdominal SRC the advantage of the SRC is convenient for construction. It does not need to perforate the beam on the type steel and speed up the construction speed.In this paper, the finite element software ABAQUS is used to compare and analyze the shear capacity of the "T" - shaped joint of six - layer concrete - shaped column frame structure.The results show that the stress state and failure process of the SRC steel joints and the SRC joints are similar, and the shear capacity of the joints decreases, but the magnitude of the decrease is not large.It is shown that the SRC node of the open abdominal acromegaly steel sheet can meet the shear capacity and greatly improve the construction efficiency.

\section{The establishment of a finite element model}

\section{Model background and analysis method}

The object of this study is the shear bearing capacity of a SRC node with an empty stomach steel plate.Its form is shown as shown in Figure 1.The " $\mathrm{T}$ " shaped solid abdominal type steel special-shaped column SRC node is shown in Figure 2. The node is taken from the six story frame structure, the site category is class III and the fortification intensity is 8 degrees $(0.2 \mathrm{~g})$. The finite element software ABAQUS is used to analyze the shear capacity of the two layer "T" joints of the structure.
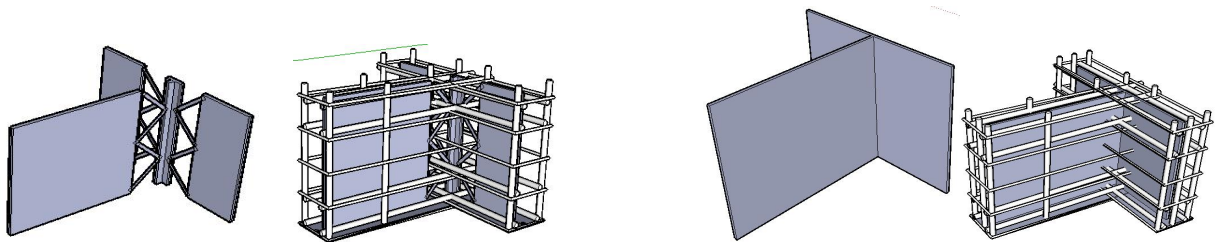

Fig. 1(Left) "T" shaped open abdominal limb steel plate type steel SRC joints

Fig. 2(Right) "T" shaped solid abdominaltype steel special-shaped column SRC node

\section{Selection of constitutive model and material parameters}

Selection of concrete constitutive model in this paper is smeared crack concrete model.A typical isotropic elastoplastic material model is used in the steel constitutive model and Yield criterion is von Mises.The type steel adopts the 8 node unit of space hexahedron, the thickness of the web is $16 \mathrm{~mm}$, the strength is $315 \mathrm{MPa}$. The parameters of concrete and steel material are shown in Table 1 .

Tab. 1: Joint information list

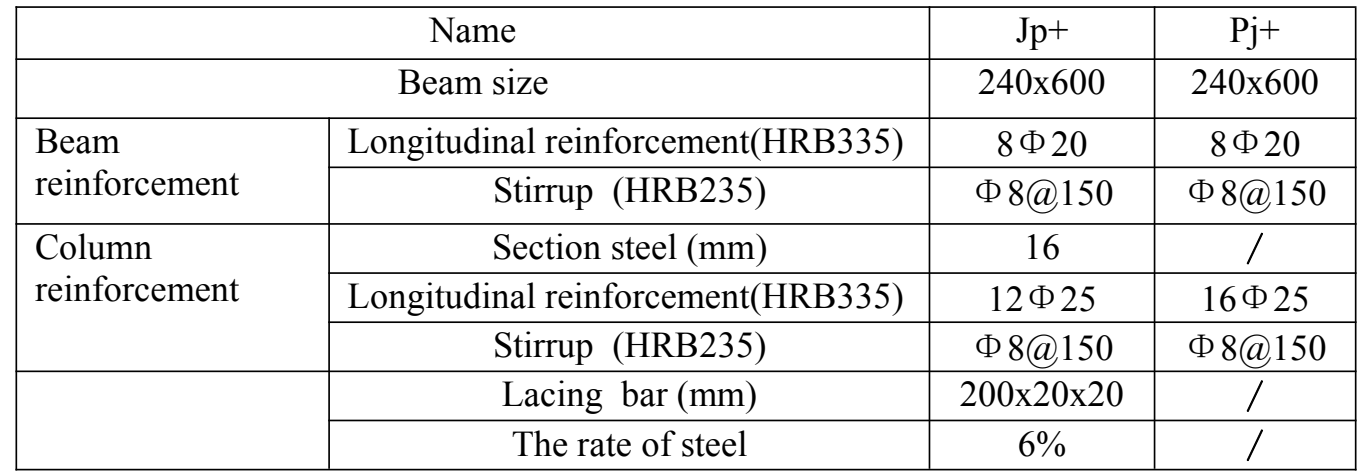




\section{Comparison and analysis of nonlinear finite element method for $T$ shaped joints}

\section{The stress process of steel plate shaped steel shaped column joints with open acromegaly}

(1)Initial crack stage:The load is about $31.5 \%$ of the limit load.The maximum main stress of joint concrete is shown in Figure 3.First, the tensile strength of concrete reaches the tensile strength of $\mathrm{C}$, and cracks appear in concrete. However, the location of cracks is moved away from the RC node for a long distance. This is due to the extension of the section steel to the beam. The stress begins to enter the descending section, the internal force is transferred to the beam, the stress of the reinforced bar increases faster, and the core area is pulled along the diagonal line.

(2)In the stage of crack development, when the load is about $45 \%$ limit loads, the tensile strength of some concrete in the drawing area of beam A and beam B also occurs. As the load continues to increase, the cracks in the $\mathrm{C}$ tensile area increase along the beam length direction. When the load reaches $75 \%$, the maximum principal stress of the concrete is shown in Figure 4, and there is no cracking phenomenon on the core area and the column. The stress of reinforcement increases rapidly in the tensile area of $\mathrm{C}$, the maximum tensile stress is $220 \mathrm{MPa}$, the maximum compressive stress appears in the compression area of beam $\mathrm{C}$, the stress is $-92 \mathrm{MPa}$, the maximum tensile stress of the hoop in the core area is $80 \mathrm{MPa}$, the stress value of the longitudinal reinforcement is much less than that of the yield strength.
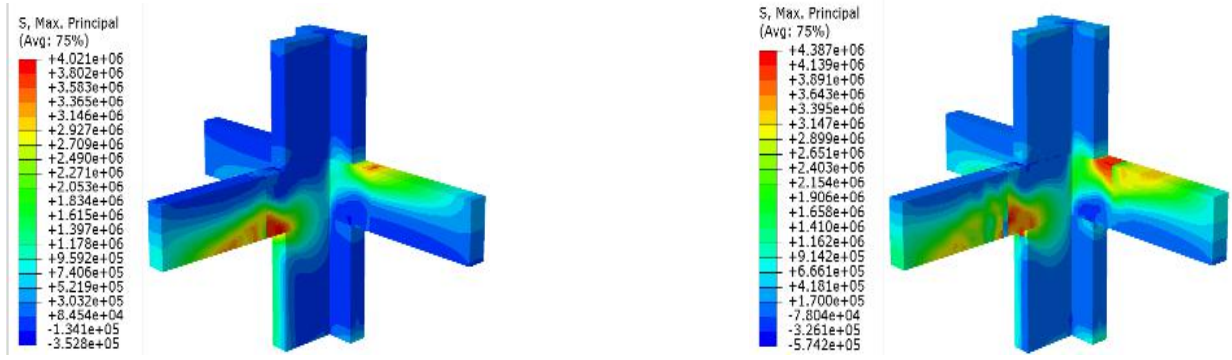

Fig. 3 (Left)Maximum principal stress at the initial crack stage

Fig. 4 (Right) Maximum principal stress in the stage of crack developmen

(3) The ultimate stage: as the load continues to increase, cracks on the beam C begin to develop rapidly, and some of the concrete in the tensile area is out of work. There is a small number of cracks in the core area of the joint, and the tension along the diagonal line. The concrete in the drawing area on the beam A and B gradually withdrew from the work. When loading to the last load step, the maximum compressive stress of the concrete on the beam is $14.3 \mathrm{MPa}$, the beam $\mathrm{C}$ reaches the ultimate bearing capacity, and the component loses its bearing capacity. The maximum principal stress of the concrete in the limit state is shown in Figure 5. At this time, the maximum tensile stress of steel bar appears in the tensile area of beam C, the stress value is $299 \mathrm{MPa}$. As shown in Figure 6 , the maximum compressive stress appears in the compressive area of beam $\mathrm{C}$, the stress value is $-122 \mathrm{MPa}$, and the maximum tensile stress in the core area of the joint is $110 \mathrm{MPa}$.
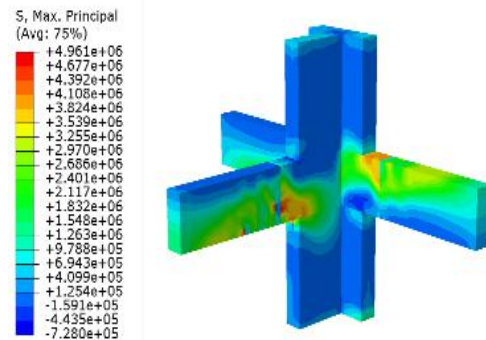

Fig. 5 concrete maximum principal stress

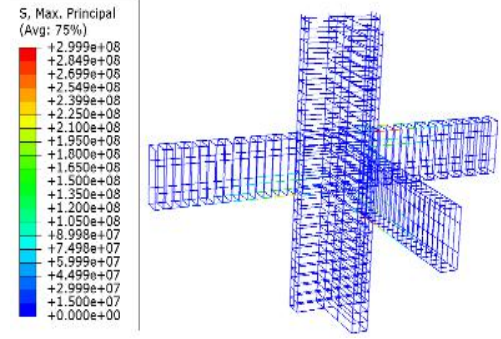

Fig. 6 maximum main stress of steel bar

\section{Stress process of real abdominal type steel special-shaped column joints}

(1)Initial crack stage: the load is about $33 \%$ of the ultimate load. The maximum principal stress of the node concrete is shown in Figure 7. First, the tensile strength of the concrete reaches the tensile strength of the girder $\mathrm{C}$, and the cracks appear on the concrete surface, which is similar to the steel 
section special-shaped column with the hollow ends. The stress begins to enter the descending section, the internal force is transferred to the beam $\mathrm{C}$, and the stress of the reinforced bar increases rapidly at the end of the beam, and the core area is drawn along the diagonal line.

(2)In the stage of crack development, when the load is about $40 \%$ limit loads, the tensile strength of some concrete in the drawing area of beam A and beam B also occurs. As the load continues to increase, the cracks in the $\mathrm{C}$ tensile area increase along the beam length direction. When the load reaches $65 \%$, the maximum principal stress of the concrete is shown in Figure 8, and there is no cracking phenomenon on the core area and the column.
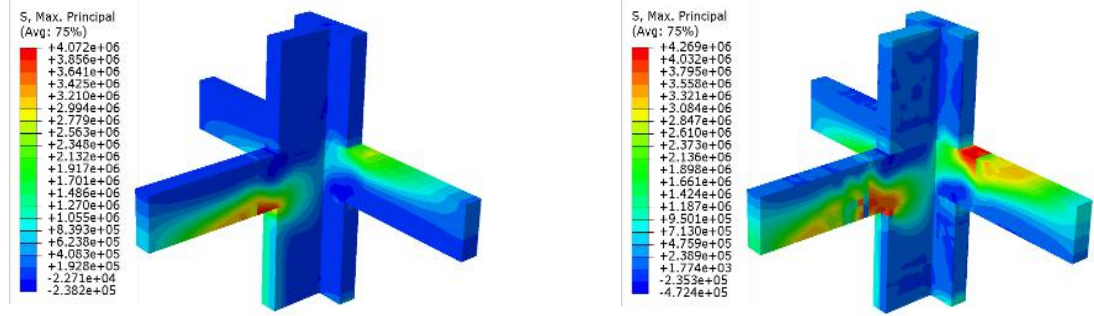

Fig. 7(Left) Maximum principal stress at the initial crack stage

Fig. 8 (Right) Maximum principal stress in the stage of crack developmen

(3)The ultimate stage: as the load continues to increase, cracks on the beam C begin to develop rapidly, and some of the concrete in the tensile area is out of work. There is a small number of cracks in the core area of the joint, and the tension along the diagonal line. The concrete in the drawing area on the beam A and B gradually withdrew from the work. When loading to the last load step, the beam $\mathrm{C}$ reaches the ultimate bearing capacity, the bearing capacity is lost, and the maximum concrete stress in the limit state is shown as shown in Figure 9. At this time, the maximum tensile stress of the steel bar appears in the tensile zone of the beam C, and the stress value is $293 \mathrm{MPa}$.

The analysis of the concrete stress in the core area during the failure of the hollow SRC joints of an acromegaly steel sheet type

(1) Analysis of the concrete stress in the core area when the node is destroyed.

Figures 10 and 11 are the $\mathrm{X}$ and $\mathrm{Y}$ shear stress clouds in the ultimate state of the core area of the node. Figure 12 and Figure 13 are the maximum principal stresses and Mises stresses of concrete under the ultimate load in the core area of the node, respectively.
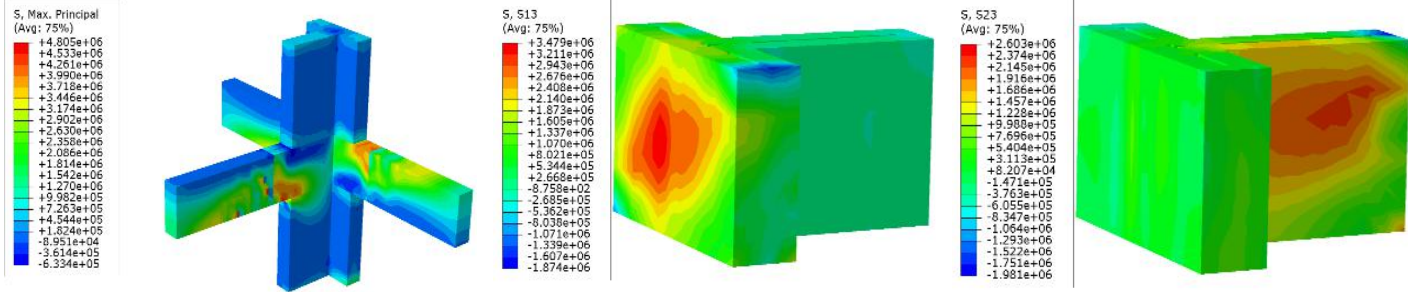

Fig. 9(Left) Maximum concrete stress in the ultimate stage

Fig . 10(Middle) The concrete stress echograms in web in the $\mathrm{X}$ direction

Fig .11(Right) The concrete stress echograms in web in the $\mathrm{Y}$ direction

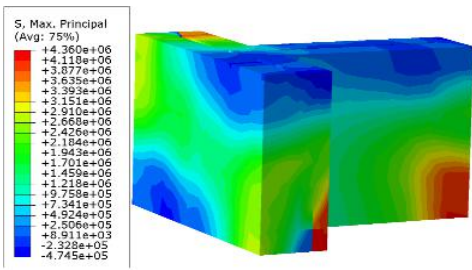

Fig .12 Axial stress echograms of concrete

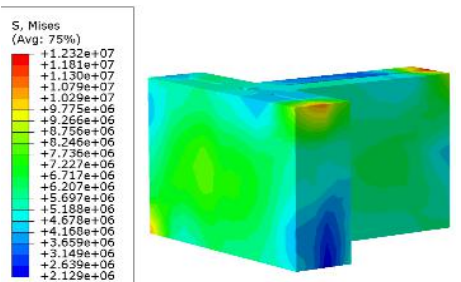

Fig .13 The maximum tensile stress of concrete

(2)Stress analysis of core zone steel during joint failure 
Figures 14, 15, 16 and 17 are the core area steel $\mathrm{X}$ to the web shear stress nephogram, the steel $\mathrm{Y}$ to the web shear stress cloud map, the steel axial stress nephogram, and the section steel maximum stress nephogram respectively.
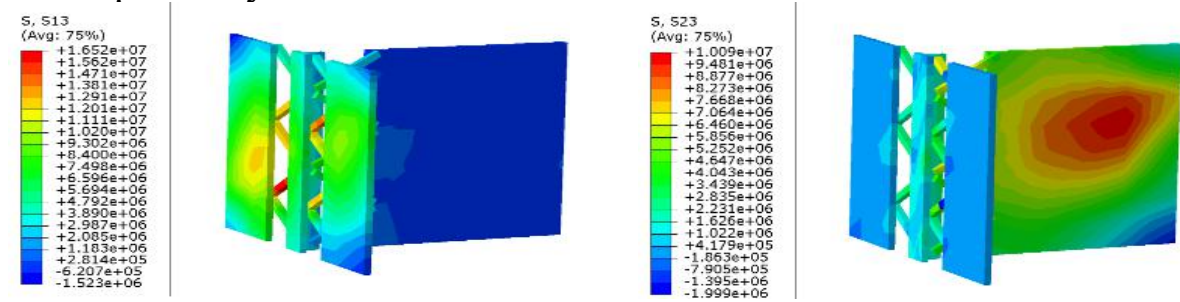

Fig .14(Left) The steel stress echograms in web in the $\mathrm{X}$ direction Fig .15(Right) The steel stress echograms in web in the Y direction
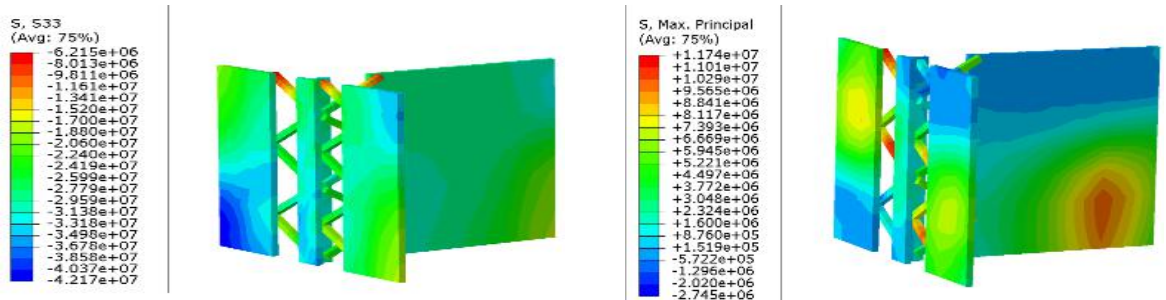

Fig .16(Left) Axial stress echograms of steel

Fig .17(Right) The maximum tensile stress of steel

\section{Analysis of concrete stress in the core area when the SRC joints of a solid steel shaped steel column are destroyed}

(1)Analysis of the concrete stress in the core area when the node is destroyed

Figures 18 and 19 are the $\mathrm{X}$ and $\mathrm{Y}$ shear stress clouds in the ultimate state of the node, respectively.
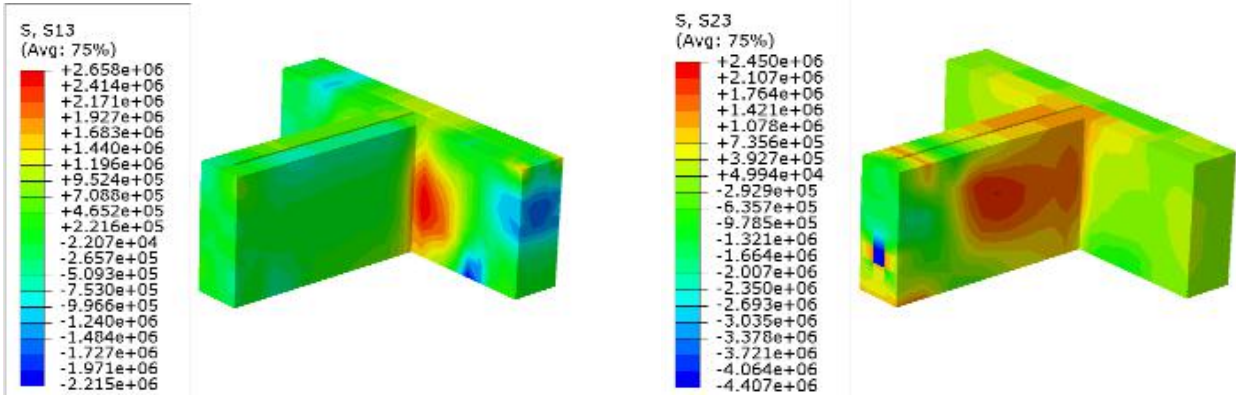

Fig . 18(Left) The concrete stress echograms in web in the $\mathrm{X}$ direction

Fig .19(Right) The concrete stress echograms in web in the Y direction

As can be seen from the diagram, the shear force on the $\mathrm{X}$ to the web is larger than that of the $\mathrm{Y}$ to the web, which is in accordance with the fasting node. In addition, the stress state is similar.

The axial stress and the maximum principal stress of the node are shown in figures 20 and 21.
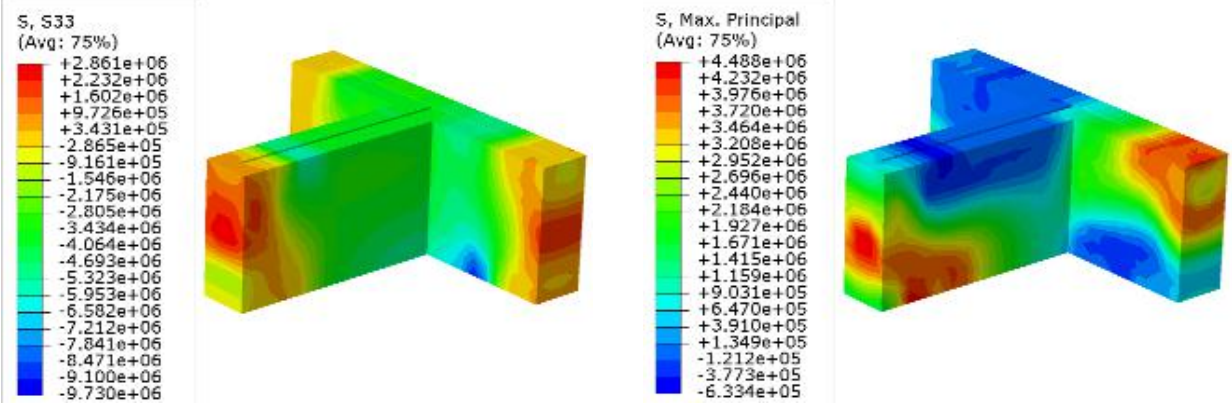

Fig .20 Axial stress echograms of concrete Fig .21 The maximum tensile stress of concrete

(2)Stress analysis of core zone steel during joint failure 


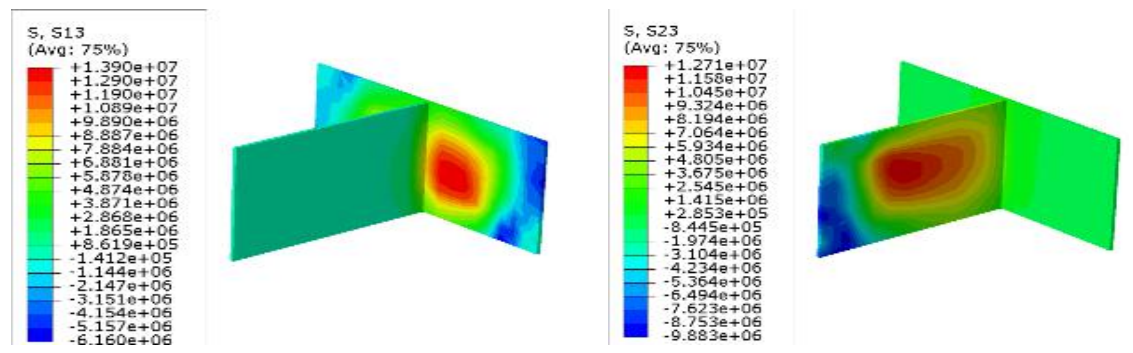

Fig .22(Left) The steel stress echograms in web in the $\mathrm{X}$ direction

Fig .23(Right) The steel stress echograms in web in the Y direction

Under the load, the column is transmitted to the two directions of the shear force $\mathrm{X}$ and $\mathrm{Y}$ in the core area of the node. Figures 24 and 25 are the core zone steel $\mathrm{X}$ and $\mathrm{Y}$ direction shear stress clouds when the real abdominal SRC nodes reach the ultimate bearing capacity.
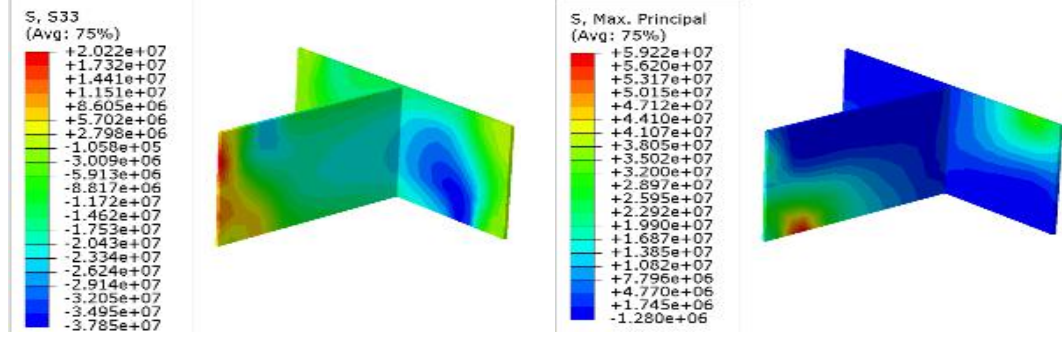

Fig .24(Left) Axial stress echograms of steel

Fig .25(Right) The maximum tensile stress of steel

Full web type steel stress distribution and the size of the hollow steel type steel acromelic is similar, along the diagonal is in tension, and the stress distribution of concrete is similar to that of the outer end of the maximum stress, because the area of plastic hinge beam cracks are also in this area came first. The first failure. From the above analysis, we can see that the bearing capacity and the stress state of the hollow steel reinforced concrete special-shaped columns are not very different from those of the solid ones. The weakening of the strip's shear strength is limited, but it can greatly improve the efficiency of the construction.

\section{Conclusions}

Under the approximate condition of steel ratio, the shear capacity of the T steel joints is only $8 \%$ lower than that of the solid web SRC nodes, and the stress state and failure process of the SRC joints are also similar. It is shown that the SRC node of the open abdominal acromegaly steel sheet can meet the shear capacity and greatly improve the construction efficiency.

\section{References}

[1] Construction Bureau of Kunming, Kunming University of Science and Technology, Tianjin University, Tongji University: the report of specially-shaped column of a six layers frame structure in the region with intensity 8 of Chinese intensity scale model for simulating the earthquake response, 2004,A20031125-416-1.

[2] Yonghong Geng, Study on shear capacity of reinforced concrete special-shaped column joints[D], Kunming University of Science and Technology Master Thesis,2007.

[3] Getting started with ABAQUS/Strandard,Hibbitt, Karlsson \& Sorensen,Inc

[4] ABAQUS/CAE User's Manual, Hibbitt, Karlsson \& Sorensen,Inc

[5] Hibbitt, Karlsson \& Sorensen, Inc. ABAQUS / Standard User's Manual; ABAQUS / CAE User, s Manual [M]. USA: HKS Co.2002. 